\title{
Perforated Appendicitis in a Neonate Presenting with Intestinal Obstruction
}

\author{
Pierrot Sarkis*
}

Department of Pediatric Surgery, Saad Specialist Hospital, Al-Khobar- 31952, Saudi Arabia

\begin{abstract}
We report a case of neonatal perforated appendicitis presenting with an early picture of intestinal obstruction secondary to entrapment of small bowel under inflamed appendix vermiformis.
\end{abstract}

Key words: Neonate, Perforated appendicitis, Internal hernia, Intestinal obstruction

\section{INTRODUCTION}

Acute appendicitis is rare in neonates. Clinical presentation is always variable and noncontributory to the diagnosis. Final diagnosis is usually confirmed during surgery, late in the course which increases the risk of morbidity [14]. We report a case of neonatal appendicitis (NA) presenting with intestinal obstruction and presented unusual operative findings.

\section{CASE REPORT}

A 21-day-old male neonate presented with fever, abdominal distension, and vomiting for two days. He had normal perinatal history (born at term with weight of $2.3 \mathrm{~kg}$ ) with normal feeding and thriving trends. On examination, his temperature was $39^{\circ} \mathrm{C}$ with peripheral cyanosis and tachycardia. Abdominal examination revealed generalized distension and tenderness. CBC showed leukocytosis $(27000 / \mu \mathrm{L})$ and CRP was $70 \mathrm{mg} / \mathrm{dl}$. Abdominal $\mathrm{X}$-ray showed few air-fluid levels. Ultrasound abdomen was unremarkable except for minimal peritoneal fluid. The patient was managed with general neonatal supportive measures and prophylactic antibiotics.

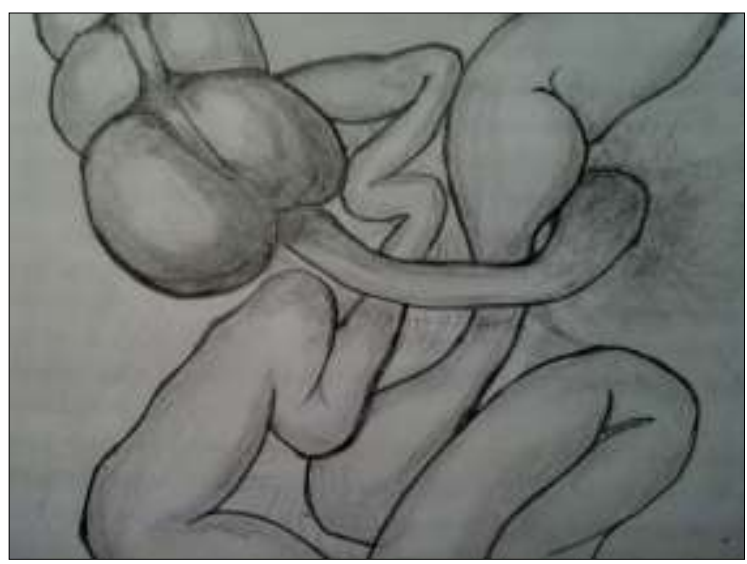

Figure 1: Illustration showing small bowel entrapment by appendix fixed at the tip.

Exploratory laparotomy was done on the same day of admission that revealed dilated small bowel loops and the last $20 \mathrm{~cm}$ of ileum was entrapped under the appendix, the tip of which was adherent with the mesentery of small bowel (Fig. 1). The appendicular tip had a perforation as well. The bowel beyond entrapment showed signs of compromised blood supply which returned progressively to normal after releasing tip of the appendix from the mesentery. No generalized peritonitis or intra-abdominal free fluid was found. Appendectomy was performed. 
Patient had uneventful postoperative period and discharged in a good general condition. Histopathology of the appendix showed acute appendicitis with inflammation of the periappendicular tissue, with normal ganglion cells. At follow-up he is thriving well with no other complaints.

\section{DISCUSSION}

Most authors relate perforation in NA to late presentation and diagnosis [4]. In contrast, the findings in the present case confirm that perforation can occur early in the process of appendicitis as also shown by cases of Khan, Gupta, and Kayastha [1-3]. Intestinal obstruction in acute appendicitis is usually attributed to local abscess or mass formation or generalized peritonitis, or it can be adhesions in late postoperative course [1-5]. In our case, there was no abscess or generalized peritonitis. Surprisingly, the short appendix fixed at its tip was entrapping small bowel through a free space between tip of perforated appendix and small bowel mesentery which led to the presentation with early signs of intestinal obstruction. This condition is scarcely reported in other age groups and termed as appendicular knot or appendicular tie syndrome $[6,7]$. To the best of our knowledge, no such case has been reported in neonates.

\section{REFERENCES}

1. Khan RA, Menon P, Rao K. Beware of neonatal appendicitis. J Indian Assoc Pediatr Surg. 2010; 15: 67-9.

2. Gupta V, Sharma SB. Neonatal appendicitis with perforation: A case report and review of literature. J Indian Assoc Pediatr Surg. 2005; 10: 179-180.

3. Kayastha K. Neonatal perforated appendicitis. J Neonat Surg. 2012; 1: 10.

4. Karaman A, Çavusoglu YH, Karaman I, Çakmak O. Seven cases of neonatal appendicitis with review of the English language literature of the last century. Pediatr Surg Int. 2003; 19: 707-9.

5. Managoli S, Chaturvedi P, Vilhekar KY, Gupta D, Ghosh S. Perforated acute appendicitis in a term neonate. Indian J Pediatr. 2004; 4; 357-8.

6. Menon T, Martin RJ, Cameron D, Rao S. Appendiceal tie syndrome. Australas Radiol. 2007; 51:B133-6.

7. Mikal S, Byers JA. Closed-loop obstruction of the ileum due to an appendical knot; report of a case. $\mathrm{J}$ Am Med Assoc. 1956; 160:49-50.

\section{Address for correspondence}

Pierrot Sarkis,

Department of Pediatric Surgery, Saad Specialist Hospital, Al-Khobar- 31952, Saudi Arabia

E mail: pierrotsarkis@hotmail.com

(c) Sarkis P, 2013

Submitted on: 01-02-2013

Accepted on: 14-03-2013

Published on: 01-04-2013

Conflict of interest: None

Source of Support: Nil

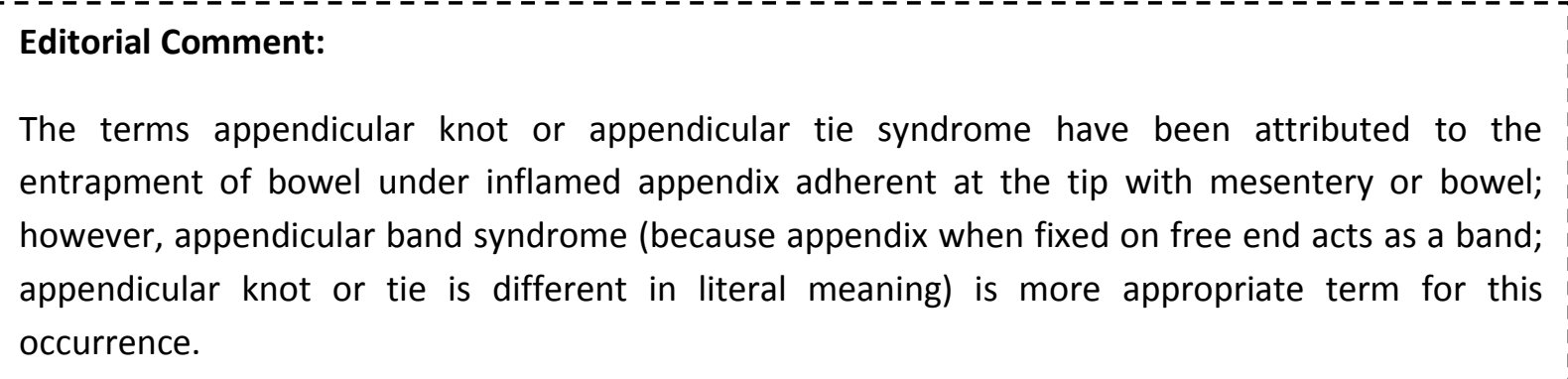

